\title{
Ética na publicação de trabalhos científicos
}

Raquel Braga*

A Declaração de Helsínquia, que define os Princípios Éticos para a Investigação Médica em Seres Humanos, foi revista em Outubro de 2013, em Fortaleza, no Brasil. Tendo sido adoptada em Helsínquia, na Finlândia, pela Associação Médica Mundial (AMM) em 1964, esta Declaração vai já na sua nona revisão. As sucessivas actualizações demonstram que os problemas éticos relativos à investigação biomédica são intemporais, mas têm sofrido evolução e reflexão. Dirigindo-se em primeira linha aos médicos, a AMM incentiva outros participantes da investigação médica em seres humanos a adoptar estes princípios. Dada a relevância deste documento no que diz respeito à salvaguarda dos direitos dos humanos e animais, ele é universalmente adoptado por quem pratica e publica investigação na área biomédica.

A Revista Portuguesa de Medicina Geral e Familiar (RPMGF) não foge a este modelo, requerendo que todos os artigos publicados respeitem os princípios éticos consagrados nesta Declaração. ${ }^{1,2}$

No entanto, temos vindo a observar que nem todos os trabalhos submetidos à RPMGF contêm, desde a sua génese ou no seu protocolo, a preocupação ética de observar a Declaração de Helsínquia, se não do ponto de vista conceptual, pelo menos do ponto de vista formal.

Acresce que, em Portugal, começam a ser desenvolvidos ensaios clínicos em Cuidados de Saúde Primários e tem aumentado o número de estudos observacionais que envolvem directamente a participação dos doentes, ou em que se utilizam dados dos processos clínicos, ou de bases de dados, sem que os doentes expressamente o autorizem.

Assim, torna-se importante focar alguns aspectos relevantes que, se não forem devidamente acautelados desde o início, prejudicam a transparência, pertinência e a bondade do processo de investigação, podendo posteriormente inviabilizar a sua publicação.

*Directora da Revista Portuguesa de Medicina Geral e Familiar
A criação de Comissões de Ética nas instituições de saúde onde se desenvolve investigação na área biomédica e, mais recentemente, nas Administrações Regionais de Saúde, veio colmatar algumas dificuldades anteriores em obter e regulamentar o parecer acerca de trabalhos de investigação que envolvem doentes ou dados dos processos clínicos.

Um dos erros mais frequentemente detectados nos trabalhos submetidos à RPMGF é a presunção de que, por se invocar a Declaração de Helsínquia, é dispensável o parecer de uma Comissão de Ética. Outro erro comum é assumir que os dois factores atrás referidos (doentes e dados clínicos) não estão necessariamente relacionados. $\mathrm{O}$ anonimato patente na publicação dos dados não dispensa as demais cautelas no manuseio $\mathrm{e}$ tratamento dos mesmos. Em primeiro lugar, o uso dos dados clínicos deverá suscitar o pedido de consentimento informado aos seus titulares. Só na impossibilidade de os obter individualmente (dado o volume de dados a aceder) e havendo reconhecida relevância ou interesse público da investigação esse pedido pode ser considerado dispensável pela Comissão de Ética em investigação. Em qualquer dos casos, a utilização de dados clínicos obriga a um pedido de autorização à Direcção da respectiva instituição de saúde ${ }^{4} \mathrm{ou}$, em casos em que haja criação de bases de dados identificáveis, à Comissão Nacional de Protecção de Dados.

Nos casos em que a pertinência ou a justificação da investigação assume interesse público, a Comissão de Ética pode considerar desnecessário o pedido de consentimento informado aos doentes, para inclusão no estudo, desde que o fornecimento dos dados seja devidamente anonimizado. ${ }^{4}$ Qualquer trabalho de investigação envolvendo seres humanos ou animais necessita de um parecer de uma Comissão de Ética e os autores não devem assumir a dispensa, a priori, do consentimento dos potenciais participantes no estudo.

É ressalvado na Declaração de Helsínquia que a investigação médica em seres humanos só deverá ser rea- 
lizada sob a direcção de pessoas com formação, treino e qualificações éticas e científicas apropriadas, exigindo a supervisão de médicos ou de outros profissionais de saúde competentes e adequadamente qualificados. ${ }^{1}$

Quer no exercício clínico quer na investigação médica, muitas intervenções implicam riscos e incómodos. ${ }^{1} A$ investigação médica em seres humanos só deve ser realizada se a importância do objectivo pretendido ultrapassar os riscos inerentes e os incómodos para os participantes na investigação. Desta forma, todos os projectos de investigação médica em seres humanos devem ser antecedidos de uma cuidadosa avaliação dos riscos e incómodos previsíveis para os indivíduos e grupos envolvidos, comparando-os com os benefícios expectáveis, para eles e para outros indivíduos ou grupos afectados pela situação sob investigação. ${ }^{1}$ Assim, será de licitude duvidosa desenvolver investigação por motivos meramente académicos, com perguntas de investigação pouco originais, que nada acrescentem ao corpo do conhecimento científico, mesmo que não acarretem riscos apreciáveis, ou mesmo que os incómodos se restrinjam à interpelação, perda de tempo ou de privacidade dos inquiridos.

Sempre que desejem publicar na RPMGF, os autores devem ter em conta que o desenho e desenvolvimento de um estudo de investigação envolvendo seres humanos devem ser claramente descritos e fundamentados num protocolo de investigação. Este deve conter um enunciado das questões éticas e indicar como foram respeitados os princípios da Declaração de Helsínquia. O protocolo deve incluir informação sobre financiamento, patrocinadores, ligações institucionais, potenciais conflitos de interesse, eventuais incentivos para os sujeitos de investigação e informação sobre ajudas e/ou indemnizações para quem seja prejudicado em consequência da participação no estudo. ${ }^{1}$ Todos estes elementos têm de ser declarados, quer no momento do recrutamento dos participantes, quer aquando da publicação do artigo.

No caso de ensaios clínicos, o protocolo deve descrever as disposições relativas às ajudas após o ensaio. ${ }^{1}$

Em todos os estudos de investigação, o desenvolvimento do estudo deve respeitar o protocolo previamente avaliado por Comissão de Ética, que procede à apreciação, orientação, comentários e parecer, devendo ser-lhe apresentadas todas as alterações necessá- rias, decorrentes dos desenvolvimentos inesperados do estudo, numa perspectiva de monitorização e por fim de comunicação das conclusões do estudo.

Outro erro comum nos trabalhos submetido à RPMGF é supor que, por os sujeitos de investigação não estarem identificados pelo nome, é o bastante para garantir a confidencialidade e privacidade. De facto, há outros elementos, como a idade, a naturalidade, a raridade do caso clínico, o contexto local, ou a instituição de saúde onde decorreu o atendimento que indirectamente revelam a identidade de um sujeito investigado, se não em termos públicos, pelo menos em termos da comunidade de investigadores interessados em determinado assunto de investigação. Devem ser tomadas todas as precauções para proteger a privacidade de cada sujeito de investigação e a confidencialidade dos seus dados pessoais. ${ }^{1}$

Algumas questões se têm colocado em determinados trabalhos submetidos à RPMGF, em termos da selecção dos sujeitos ou da amostra, que inviabilizam à partida a publicação de determinados estudos, que de outra forma, respeitando os preceitos éticos, poderiam ter interesse para publicação.

A participação de pessoas capazes de dar consentimento informado tem de ser voluntária. Nenhuma pessoa capaz deve ser seleccionada para um projecto de investigação sem que livremente o tenha aceite, ainda que possa ser apropriado consultar membros da família ou líderes comunitários em alternativa. ${ }^{1}$

O potencial participante, depois de devidamente informado dos riscos, benefícios, incómodos, conflitos de interesses, etc., tem de ser informado do direito a recusar-se a participar no estudo ou de, em qualquer altura, revogar o consentimento de participar sem represálias. ${ }^{1}$ Caso a proposta de integração no estudo ou a recusa possa afectar a relação médico-doente, esta deve ser feita por elementos devidamente qualificados, estranhos a esta relação, para que o potencial sujeito do estudo não se sinta sob coação e tal não possa prejudicar a relação médico-doente, no futuro.

Se o consentimento não pode ser efectuado por escrito, o consentimento verbal tem de ser formalmente documentado e testemunhado.

O uso de dados ou de material humano identificáveis, incluindo material e dados de biobancos ou repositórios afins, obriga a um pedido de parecer para a sua 
recolha, guarda ou reutilização. Pode haver situações excepcionais em que a obtenção de consentimento seja impossível ou impraticável, pondo em causa a validade da investigação. Nestas circunstâncias, a investigação apenas pode ser feita após apreciação e aprovação por uma Comissão de Ética para a investigação. ${ }^{1}$

Para além das questões éticas a nível da investigação, abordadas pela Declaração de Helsínquia, cuja não observação infelizmente tem condicionado a recusa de alguns artigos com potencial de publicação, surgem por vezes também questões de ética na publicação, nomeadamente a nível de autoria dos trabalhos submetidos. Estas questões já foram exaustivamente abordadas em editorial anteriormente publicado na RPMGF, cuja leitura se recomenda vivamente. ${ }^{5}$

Um autor é alguém que contribuiu substancialmente para elaboração do trabalho, o que inclui a participação na concepção, escolha da metodologia, recolha e análise de dados, escrita e edição do trabalho. É também alguém que assume a responsabilidade pelo que foi publicado. ${ }^{6}$ Deste modo, aqueles que de alguma forma deram contribuições relevantes em qualquer fase de investigação ou de redacção do artigo, mas não preenchem todos os critérios de autoria podem ser citados, com o devido consentimento, na secção dos agradecimentos.

Em trabalhos de investigação de dimensão local, com amostras de reduzida dimensão, ou em casos clínicos desenvolvidos em contexto de cuidados de saúde primários, por vezes, as listas intermináveis de autores colocam questões relativas ao cumprimento de todos os critérios de autoria, merecedoras de melhor cuidado.

Depois de isolados alguns dos erros mais frequentes na condução de trabalhos de investigação, e depois de salientadas algumas recomendações patentes na nova versão da Declaração de Helsínquia, é importante aconselhar os investigadores a que, no momento de planearem e desenharem o protocolo dos seus trabalhos de investigação, consultem desde logo as Normas de Publicação da revista à qual desejam submeter o arti- go, para que possam acautelar e reflectir acerca de todos os preceitos éticos. A RPMGF tem normas ${ }^{2}$ explícitas que regulam estas questões e tem publicado artigos de reflexão nesta área, como a Carta aberta a um jovem investigador clinico. ${ }^{7}$ Este tipo de artigo constitui um precioso guia de orientação nas complexas questões da ética em investigação biomédica. A sua leitura previne erros por vezes impossíveis de remediar a posteriori, quando estes são inadvertidamente detectados no decurso ou no final de um penoso processo de investigação.

O corpo editorial da RPMGF está sempre atento aos problemas éticos, reflectindo e ajustando as respostas às novas e velhas questões, face às novas realidades $\mathrm{e}$ circunstâncias em que se desenvolve a investigação e a publicação de trabalhos científicos. A principal preocupação e razão desta reflexão ética dinâmica é a protecção dos doentes, a sua saúde e os seus direitos, a par do desenvolvimento científico e do bem comum.

\section{REFERÊNCIAS BIBLIOGRÁFICAS}

1. World Medical Association.WMA Declaration of Helsinki - Ethical Principles for Medical Research Involving Human Subjects. Disponível em: http://www.wma.net/en/30publications/10policies/b3/ [acedido em 27/11/2013].

2. Normas para apresentação de artigos à Revista Portuguesa de Clínica Geral. Rev Port Clin Geral 2010 Mai-Jun; 26 (3): 325-40.

3. Art. $^{\circ} 4 .^{\circ}$, Lei n. $^{\circ} 12 / 2005$, de 26 de Janeiro. Diário da República, $1^{\text {a }}$ série.

4. Art. $^{\circ} 26^{\circ}$, Decreto-Lei ${ }^{\circ} 253$, de 2012 de 27 de Novembro. Diário da República, $1 .^{\mathrm{a}}$ série.

5. Yaphe J.Who is an author? A fresh look at the rules and ethics of scientific authorship. Rev Port Clin Geral 2011 Jul-Ago; 27 (4): 331-2.

6. International Committee of Medical Journal Editors. Uniform Requirements for Manuscripts Submitted to Biomedical Journals: Writing and Editing for Biomedical Publication. Disponível em: http://www.ICMJE.org [acedido em 27/11/2013].

7. Almeida R. Carta aberta a um jovem investigador clínico. Rev Port Clin Geral 2011 Nov-Dez; 27 (6): 499-500.

\section{CONFLITO DE INTERESSES}

A autora declara não ter conflito de interesses.

ENDEREÇO PARA CORRESPONDÊNCIA

director@rpmgf.pt 